\title{
Crosstalk of ER Stress, Mitochondrial Membrane Potential and ROS Determines Cell Death Mechanisms Induced by Etoposide Loaded Gelatin Nanoparticles in MCF-7 Breast Cancer Cells
}

\author{
Imran Moin, Largee Biswas, Disha Mittal, Ankita Leekha, Namrata Kumari and Anita K. Verma*
}

Department of Zoology, Nanobiotech Lab, Kirori Mal College, University of Delhi, Delhi 110007, India

\begin{abstract}
Background: Despite awareness, early diagnosis, advanced therapeutics, breast cancer cure is yet elusive, being the leading cause of death worldwide. Etoposide (Etop) is used against diverse tumors but its clinical use is limited by lipophilicity and adverse effects. Hence, novel strategies and therapeutic molecules against breast cancer urgently need to be investigated.

Methods: Gelatin nanoparticles (GNPs) were synthesized by two-step desolvation, characterized by TEM, DLS, and zeta potential. We elucidated the role of Etop, Etop loaded Gelatin Nanoparticles(EGNP) and GNP on breast cancer cells(MCF-7) and human embryonic kidney cells(HEK) by biocompatibility evaluation(MTT Assay), DNA-Fragmentation analysis (DPA Assay), Cellular uptake, Intracellular ROS analysis(DCFDA), biochemical assay(GST, GSH, GPx, GR, SOD, LDH and NO), Mitochondrial Membrane Potential(MMP) estimation(Rhodamine-123), $\mathrm{Ca}^{2+}$ signalling (Fluo4-AM) and flow-cytometry.

Results: The size distribution, PDI and zeta potential of GNPs were $150 \pm 12 \mathrm{~nm}, 0.257 \pm 0.14$, and $-31.4 \pm 4.69$ $\mathrm{mV}$ (Entrapment-Efficiency $\sim 70 \%$ ). The $\mathrm{IC}_{50}$ of EGNPs and Etop per se was $74.14 \mu \mathrm{g} / \mathrm{mL}$ and $142.67 \mu \mathrm{g} / \mathrm{mL}$ post 24 hrs in MCF-7, respectively. Maximum DNA-fragmentation was induced by EGNP in MCF-7, as compared to HEK. Reduced GSH, GPx, GR, SOD levels and increased GST, LDH and NO levels were observed in MCF-7 treated by EGNP, whereas HEK were unaffected. EGNP enhanced intracellular ROS generation in MCF-7 leading to increased ER-stress with significant loss of MMP. FACS analysis indicated only $6 \%$ and $25 \%$ cells in Apoptosis, $23 \%$ and $5 \%$ Necrosis, $66 \%$ and $2 \%$ necroptosis, post-treatment with EGNP and Etop per se, respectively. EGNPs augments the activity of Etop by inducing high ER-stress, Mitochondrial impairment causing bioenergetic catastrophe, ROS generation and calcium homeostasis dysregulation preferentially in cancer cells culminating in necroptosis, thereby modulating the cell-death mechanisms from apoptosis to necroptosis.
\end{abstract}

Conclusions: The susceptibility of cancer cells to metabolic insults offers a selective therapeutic window that can be exploited to abrogate the cell-survival mechanisms by our reported EGNPs, while, the physiological levels of ROS in normal cells rendered them ineffective to continued oxidative insults.

Keywords: Etoposide; Gelatin nanoparticles; Cytotoxicity; ROS; $\mathrm{Ca}^{2+}$ signaling; ER stress; Apoptosis; Necroptosis

\section{Introduction}

Maximum patients diagnosed with cancer are suffering from breast cancer worldwide, and is considered the most distressing cancer among women today. According to the Indian Union Health Ministry, for females in India, breast cancer ranks as the topmost cancer with a high rate of 25.8 per 100,000 women with the mortality rate of 12.7 per 100,000 women. Accordingly it is predicted that at least 1,797,900 women in India may probably have breast cancer by 2020. In India, breast cancer continues with a low survival rate with only $~ 66 \%$ women that were diagnosed with breast cancer between 2010 and 2014 are still surviving [1]. Hence, novel strategies and therapeutic molecules against breast cancer urgently need to be investigated.

Etoposide (VP-16) (Etop) is preferentially used to treat small cell lung cancer, lymphomas, testicular cancer, leukemias, ovarian, cervical, lung, and testicular cancer but is used as a combination therapy for breast and ovarian cancer. Etop is an anti-cancer drug derived from podophyllotoxin, a natural product from plant Podophyllum peltatum [2]. Etop inhibits tubulin polymerisation leading to its anti-mitotic activity [3], by inhibiting the ligation activity of topoisomerase II enzyme during cell division that leads to fragmentation of genome [4]. The major limitation for the use of Etop is its lipophilicity, coupled with the carrier material that adds to the adverse effects. Previous reports suggested that Etop may possess atypical cytotoxic activities such as the activation of caspase- 3 , the initiation of reactive oxygen species (ROS), the induction of Akt/mTOR signalling [5,6]. Furthermore, the action of Etop can either be p53-dependent or p53-independent $[7,8]$. The signalling mechanism responsible for initiation of intracellular apoptosis by Etop is not clearly understood as it may differ with each cell type.

Intravenously administered Etop formulations are quickly eliminated from the blood circulation and produce myelo-suppression, although the effects of Etop depend both on its concentration and its duration of action [9], one of the most promising properties of nanoparticles include their ability to act as carriers for different

${ }^{*}$ Corresponding author: Anita K. Verma, Department of Zoology, Nanobiotech Lab, Kirori Mal College, University of Delhi, Delhi 110007, India, Tel: 911127667861 E-mail: akverma@kmc.du.ac.in

Received: August 09, 2018; Accepted: August 27, 2018; Published: August 31, 2018

Citation: Moin I, Biswas L, Mittal D, Leekha A, Kumari N, et al. (2018) Crosstalk of ER Stress, Mitochondrial Membrane Potential and ROS Determines Cell Death Mechanisms Induced by Etoposide Loaded Gelatin Nanoparticles in MCF-7 Breast Cancer Cells. J Nanomed Nanotechnol 9: 513. doi: 10.4172/2157-7439.1000513

Copyright: @ 2018 Verma AK, et al. This is an open-access article distributed under the terms of the Creative Commons Attribution License, which permits unrestricted use, distribution, and reproduction in any medium, provided the original author and source are credited. 
Citation: Moin I, Biswas L, Mittal D, Leekha A, Kumari N, et al. (2018) Crosstalk of ER Stress, Mitochondrial Membrane Potential and ROS Determines Cell Death Mechanisms Induced by Etoposide Loaded Gelatin Nanoparticles in MCF-7 Breast Cancer Cells. J Nanomed Nanotechnol 9 : 513. doi: $10.4172 / 2157-7439.1000513$

Page 2 of 9

drugs which are dissolved, entrapped, encapsulated and attached to the nanoparticle matrix. The advantages of using nano drug delivery system include the size and surface modification of nanoparticles for both active and passive targeting after administration. Increased drug efficacy and reduction in side effects owing to controlled drug release at the site of localisation coupled with encapsulation of drugs without any chemical reaction to conserve the drug activity are added advantages [10]. Gelatin is a biodegradable, biocompatible, versatile biopolymer [11] whose application in developing pharmaceutical formulations, demonstrated over the past decade, justifies its immense usefulness [12]. Gelatin nanoparticles can be synthesized by various methods like desolvation, coacervation, emulsification or nanoprecipitation. Since polymeric nanocarriers do not have their own cytotoxicity they can help optimize the therapeutic efficacy and greatly reduce the side effects of systemic chemotherapy [13]. Several carrier systems including liposomes, micelles, microcapsules, macromolecules, lipid emulsions, and solid lipid nanoparticles, have been evaluated for effective chemotherapy to deliver antitumor agents to target sites [14]. The purpose of the present investigation was to synthesize and characterize EGNPs (Etoposide loaded Gelatin Nanoparticles) and to evaluate their influence on the proliferation, cellular uptake in MCF-7 and HEK-293 cell line. To elucidate the genotoxic and carcinogenic potential, it was imperative to assess the role of ER stress on intracellular levels of ROS and $\mathrm{Ca}^{+2}$ signalling leading to induction of cell death.

\section{Materials and Methods}

\section{Preparation of nanoparticles}

$5 \%$ gelatin (type-B; 75 bloom) was dissolved in $25 \mathrm{ml}$ of distilled water $\left(\sim 50^{\circ} \mathrm{C}\right)$ and degraded under UV light at room temperature (RT). The gelatin solution was titrated with an equal volume of acetone. The clear supernatant was discarded carefully without disturbing the precipitate that was dissolved in an equal volume of warm deionised water $\left(\sim 50^{\circ} \mathrm{C}\right)$ and the $\mathrm{pH}$ adjusted to 2.5 . A second step desolvation using an equal volume of acetone was done and $250 \mu \mathrm{l}$ of $7 \%$ glutaraldehyde was added dropwise. L-cysteine was added later after stirring. The clear supernatant was discarded after centrifugation at $20000 \mathrm{~g}$ for $19 \mathrm{~min}$. The pellet was washed twice with $30 \%$ acetone. After the final washing, the pellet was re-suspended in half the volume of acetone and stirred overnight. The slightly turbid solution having nanoparticles was harvested after $24 \mathrm{~h}[15,16]$.

\section{Transmission Electron Microscopy (TEM)}

The shape and size of the nanoparticles was assessed by TEM [Philips EM300, 80kV]. The samples were mounted on the carboncoated copper grid (mesh size 300), and then air dried. This loaded grid was kept in the desiccator before loading on to the microscope. Image contrast was provided by exposing the sample to $2 \%$ uranyl acetate.

\section{UV-Vis Spectrophotometer}

The absorption spectra of the nanoparticles and gelatin polymer was done in the range of $200-600 \mathrm{~nm}$ in by a UV spectrophotometer having a monochromator/xenon flash system with a silicon diode detector for absorbance and a tungsten halogen lamp with blocking interference filters (Cary 60 UV vis, Agilent Technologies) using Cary Win UV software.

\section{Entrapment Efficiency (EE\%)}

Etop was dissolved in DMSO and added to a known concentration of nanoparticles solution by bath sonication. The free Etop was physically entrapped in GNPs. The EGNP were separated from the free Etop after filtering the solution through a $100 \mathrm{KDa}$ cut off Millipore filter [UFP2THK24] and absorbance of free Etop was obtained using a spectrophotometer (Cary 60 UV vis, Agilent Technologies) [17].

The EE\% was calculated as:

$\mathrm{EE}(\%)=\frac{[\text { Drug]total }-[\text { Drug }] \text { free }}{[\text { Drug }] \text { total }} \times 100$

where, (Drug total and Drug free) are the amount of total Drug added and free Drug respectively.

\section{Cytotoxicity assay}

Human Breast cancer cells MCF-7 (Michigan Cancer Foundation) and normal cells HEK-293 (Human Embryonic Kidney) were obtained from NCCS, Pune, and maintained in RPMI-1640 supplemented with $10 \% \mathrm{FBS}$. Cells were proliferated at $37^{\circ} \mathrm{C}$ in a humidified $\mathrm{CO}_{2}$ incubator (Thermo Scientific, USA).

Cytotoxicity of Etop per se, EGNP and void nanoparticles was measured by previously published protocol [18]. $5 \times 10^{3}$ cells/well were plated in a 96 well microtitre plate. Cells were exposed to various concentrations of Etop per se, EGNP and void nanoparticles and were incubated at $37^{\circ} \mathrm{C}$ for $24 \mathrm{~h}$ and $48 \mathrm{~h}$ respectively. $20 \mu \mathrm{l}$ of MTT solution $(5 \mathrm{mg} / \mathrm{ml})$ was added to the plate and carefully after $4 \mathrm{~h}$, the media was removed without disturbing the cells. Formazan crystals formed by the reactions were dissolved in DMSO, and absorbance was determined at $540 \mathrm{~nm}$ in a UV-spectrometer. The $\mathrm{IC}_{50}$ values were calculated by plotting the drug concentration versus the survival ratio of the treated cells.

$$
\frac{([\mathrm{A}] \text { test } /[\mathrm{A}] \text { control })}{[\mathrm{A}] \text { control }} \times 100
$$

where,

[A] test is absorbance of the test sample, and [A] control is the absorbance of the control sample.

\section{Cellular uptake}

Exponentially growing cells (HEK-293 and MCF-7) were seeded at density of $1 \times 10^{4}$ cells/well on $12 \mathrm{~mm}$ round glass cover slip in a 24 well microplate supplemented with $500 \mu \mathrm{RPMI}-1640+10 \%$ FBS. Cells were treated with FITC-GNP and DAPI for $3 \mathrm{~h}$. They were washed twice with PBS ( $\mathrm{pH} 7.4$ ), to remove un-internalized nanoparticles. The cells were fixed by $4 \%$ paraformaldehyde and the slides were mounted in DPX. After that these slides were observed under fluorescent upright microscope (Nikon Eclipse 90i) under bright field and UV filter [18].

\section{Quantitative test for DNA fragmentation}

Diphenylamine (DPA) assay assay was performed as per the protocol of Gercel-Taylor, 2005 [19]. Untreated and treated cells (5 x $10^{6}$ cells) were resuspended in $800 \mu \mathrm{l}$ of $10 \mathrm{mM} \mathrm{PBS}, \mathrm{pH} 7.4$, and 700 $\mu \mathrm{l}$ of ice-cold lysis buffer [( $5 \mathrm{mM}$ Tris- $\mathrm{HCl}, 20 \mathrm{mM}$ EDTA, $\mathrm{pH}$ 8.0, $0.5 \%(\mathrm{v} / \mathrm{v})$, Triton X-100]. The lysate was transferred to the tubes and incubated on ice for $15 \mathrm{~min}$, which was further centrifuged for $15 \mathrm{~min}$ at $4^{\circ} \mathrm{C}(13,000 \mathrm{~g})$. The supernatant was collected and transferred to a new tube. The pellet was resuspended in $1.5 \mathrm{ml}$ TE buffer ( $1 \mathrm{mM}$ EDTA, $10 \mathrm{mM}$ Tris, $\mathrm{pH} 8.0$ ). $1.5 \mathrm{ml}$ of $10 \%$ TCA was added to each tube and kept for $10 \mathrm{~min}$ at RT. The mixture was again centrifuged, supernatant was decanted and the pellet was resolublised in $0.7 \mathrm{ml}$ of $5 \%$ TCA. This 
Citation: Moin I, Biswas L, Mittal D, Leekha A, Kumari N, et al. (2018) Crosstalk of ER Stress, Mitochondrial Membrane Potential and ROS Determines Cell Death Mechanisms Induced by Etoposide Loaded Gelatin Nanoparticles in MCF-7 Breast Cancer Cells. J Nanomed Nanotechnol 9: 513. doi: $10.4172 / 2157-7439.1000513$

Page 3 of 9

mixture was heated at $80^{\circ} \mathrm{C}$ for $15 \mathrm{~min}$, then cooled to $\mathrm{RT}$ and was again centrifuged at $1600 \mathrm{rpm}$. The supernatant $(0.5 \mathrm{ml})$ was transferred to a fresh micro-centrifuge tube and $1 \mathrm{ml}$ diphenylamine reagent was added and incubated at $30^{\circ} \mathrm{C}$ overnight. The absorbance was measured at 600 $\mathrm{nm}$. The percent DNA fragmentation was evaluated by the following formula:

$\%$ DNA Fragmentation $=\frac{\text { O.D }_{\cdot 600} \text { of the supernatant }}{\left[\text { O.D. }_{600} \text { of the supernatant }+ \text { O.D }_{600} \text { of the pellet }\right]}$

\section{Intracellular detection of ROS generation by DCF-DA Assay}

$1 \times 10^{6}$ cells were seeded in petri-plates and grown overnight in RPMI-1640 supplemented with 10\% FBS, and next day treated with various treatment groups i.e. Etop, GNP, EGNP. Post-treatment, the cells were harvested and $25 \mu \mathrm{M}$ of DCF-DA was incubated with cells at $37^{\circ} \mathrm{C}$ for $40 \mathrm{~min}$, the plates were kept away from light by wrapping the plate in aluminium foil. Fluorescence intensity in arbitrary units was measured using spectro-fluorimeter (Agilent Technologies, U.S.A) with an excitation at $485 \mathrm{~nm}$ and emission at $529 \mathrm{~nm}$, respectively, with the slit widths adjusted to 5.0 [20].

\section{Assessment of intracellular $\mathrm{Ca}^{2+}$ signaling}

The concentration of intracellular $\mathrm{Ca}^{2+}$ was measured with Fluo4/AM. HEK-293 and MCF-7 cells were treated with GNP, Etop, EGNP for $24 \mathrm{~h}$, the supernatant was removed and the treated cells were incubated with Fluo-4/AM $(10 \mu \mathrm{M})$ for $30 \mathrm{~min}$ at $37^{\circ} \mathrm{C}$, washed twice with PBS to remove unspecific staining, then moderate PBS was added to cover the cells. The fluorescent intensity of Fluo-4/ AM was quantified by a fluorescent micro-plate reader (TECAN, Switzerland) with an excitation and emission at $490 \mathrm{~nm}$ and 526 $\mathrm{nm}[21]$.

\section{Mitochondrial Membrane Potential (MMP)}

MMP assay was done by flow cytometry [22] and determined using the fluorescent dye Rhodamine 123. Briefly, $1 \times 10^{6}$ cells/well of HEK-293 and MCF-7 cells were plated in a 6 well plate and allowed to adhere overnight. The cells were treated with $100 \mu \mathrm{g} / \mathrm{ml}$ of Etop, GNP and EGNP at $37^{\circ} \mathrm{C}$ for $24 \mathrm{hr}$. After treatment, the cells were trypsinised and collected in $15 \mathrm{ml}$ centrifuge tube, washed by PBS and $5 \mu \mathrm{g} / \mathrm{ml}$ of Rhodamine 123 was added. After incubation of $30 \mathrm{~min}$ at $37^{\circ} \mathrm{C}$, cells were washed with PBS (10 mM, pH 7.4). Finally, the cells were resuspended in $500 \mu \mathrm{l}$ PBS and fluorescent intensity was measured by flow cytometer (BD Biosciences) and analysed using Cell Quest software Caliber. All experiments were performed in triplicates. Untreated cells were taken as a control.

\section{Annexin V/PI analysis}

Etop induced apoptosis was evaluated by bivariate staining of cells with Annexin V-fluorescein isothiocyanate (FITC) Apoptosis Detection Kit (556547, BD Biosciences). In brief, approximately $1 \mathrm{x}$ $10^{6}$ cells/well were plated in a six-well plate at $37^{\circ} \mathrm{C}$ overnight in $\mathrm{CO}_{2}$ incubator; the cells were then incubated with Etop, GNP and EGNP for $24 \mathrm{hr}$. The cells were harvested and washed twice with cold PBS. After that cells were suspended in $100 \mu \mathrm{L}$ of Annexin V binding buffer and kept with $5 \mu \mathrm{L}$ of FITC-conjugated Annexin $\mathrm{V}$ and $5 \mu \mathrm{L}$ of propidium iodide (PI) for $15 \mathrm{~min}$ in the dark as per the instructions of the kit. Furthermore, Annexin V binding buffer $(200 \mu \mathrm{L})$ was added to each tube. The cells were eventually examined using a BD FACSCalibur II flow cytometer (BD Biosciences, CA). All the set of experiments were done in triplicates.

\section{Statistical analysis}

The results were expressed as Mean standard deviation. Comparison among groups were analysed by One-way ANOVA and means were separated by Tukey's test using Prism (5.0) software (Prism software Inc. CA). Levels of significance were accepted at $\leq 0.05$ level.

\section{Results and Discussion}

Biopolymeric nanoparticles are currently in demand for improved delivery of hydrophobic anti-cancer molecules. Gelatin Nanoparticles (GNPs) were synthesised by two-step desolvation method that ensures homogenous nanoparticles under controlled parameters as decreasing or increasing the $\mathrm{pH}$ causes the alteration in net positive or negative charges mainly due to ionization of $\mathrm{NH}_{2}$ and $\mathrm{COOH}$ groups, respectively [16]. Glutaraldehye was used as a crosslinker to saturate the number of functional amino groups that were available for covalent bonding of amino-reactive ligands. The size depends on the number of crosslinks but to avoid toxicity from free aldehyde groups, the cross linker was used in as low volume as possible. Further, L-cysteine was also used to quench any aldehyde groups that could possibly generate free sulfhydryl groups on the surface of gelatin nanoparticles [15]. The physical characterization of nanoparticles depicted in Figure 1A-1C indicated the TEM, size distribution of the nanoparticles by DLS and zeta potential, respectively. Unimodal distribution of nanoparticles was evident by DLS with maximum percentage intensity to be $\sim 170$ $\mathrm{nm}$. The average surface charge of the GNP was $-31.4 \pm 4.69 \mathrm{mV}$ that confers sufficient colloidal stability. TEM exhibits a marginally smaller but good correlation with DLS showing the diameter to be $\sim 150 \mathrm{~nm}$, as the TEM involves imaging of the dry nanoparticles while DLS is a measure of the hydrodynamic diameter. TEM image clearly indicated a spherical morphology (Figure 1).

Etop was physically entrapped in GNPs by bath sonication with an $\mathrm{EE} \sim 70 \%$. Precise control of degradation and drug release kinetics depends extensively on the physico-chemical properties of gelatin, such as the polydispersity index, molecular weight, crystallinity and hydrophobicity of the drug. Gelatin is a low charge density polyelectrolyte and its net charge in solution gets strongly affected by the prevailing $\mathrm{pH}$ conditions. Hence, altering the $\mathrm{pH}$ led to significant changes in final particle size making them smart, $\mathrm{pH}$ responsive nanoparticles that can be therapeutically exploited in situations in patients with solid tumours have an acidic microenvironment [16].

Cellular Uptake of FITC-GNPs in MCF-7 cells was considerably higher when compared to HEK-293 cells as visualized by fluorescence

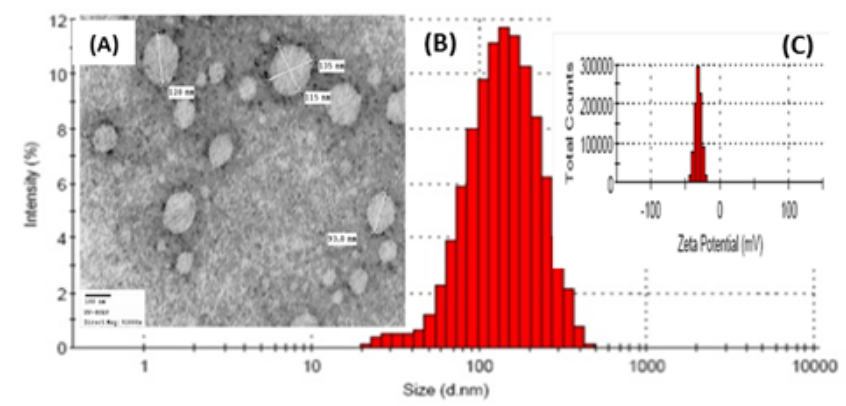

Figure 1: $1 \mathrm{~A}-1 \mathrm{C}$ indicated the TEM, Size distribution by DLS of the nanoparticles $(\sim 170 \mathrm{~nm})$ and zeta potential $(-31.4 \pm 4.69 \mathrm{mV})$. TEM image indicated a spherical morphology. Electrophoretic mobility of nanoparticle was also high $\sim 3.6$ to $1.6 \mu \mathrm{mcm} / \mathrm{Vs}$ which confirmed that the size is in nano range. 
Citation: Moin I, Biswas L, Mittal D, Leekha A, Kumari N, et al. (2018) Crosstalk of ER Stress, Mitochondrial Membrane Potential and ROS Determines Cell Death Mechanisms Induced by Etoposide Loaded Gelatin Nanoparticles in MCF-7 Breast Cancer Cells. J Nanomed Nanotechnol 9 : 513. doi: $10.4172 / 2157-7439.1000513$

microscopy. They appeared to be internalized and deported to the cytoplasm and the nuclei were counterstained with DAPI (Figure 2). This result could be extrapolated to the fact that the EGNPs were internalized more into the cancer cells. Also, the GNPs protected and inhibited the degradation of Etop from intracellular metabolic insults, thereby, providing an intracellular concentration gradient of the drug. While Etop per se in a solution form is vulnerable to the severe internal environment, leading to quick degradation and hence not being able to effectively exhibit the anti-proliferative effect that requires increased dosage. Owing to the sustained release of Etop from EGNPs, the drug acts for prolonged time period within the cells, thereby exhibiting its therapeutic potential.

It was necessary to assess the biocompatibility of Etop, GNP and EGNP on MCF-7 and HEK-293 cells by the colorimetric MTT cell viability assay. It involves the reduction of yellow coloured MTT into purple coloured formazan crystals that was proportional to the cellular metabolic activities due to $\mathrm{NAD}(\mathrm{P}) \mathrm{H}$-dependent cellular oxidoreductase enzymes in living cells $[23,24]$. This precise quantification of changes in the rate of proliferation or cell viability is routinely assessed as a linear relationship between metabolically dynamic cells and the produced colour.

The Table 1 represents the $\mathrm{IC}_{50}$ of the treatment groups, wherein it was clear that GNP had negligible cytotoxicity on both the cell lines. EGNP was observed to have maximum anti-cancer efficacy at half the concentration of Etop per se in MCF-7 cell line post $24 \mathrm{~h}$ (Figures 3 and 4). Based on the results, $100 \mu \mathrm{g} / \mathrm{ml}$ dose of Etop per se and equivalent Etop in EGNP was selected for further mechanistic studies.

Anti-oxidants and oxidants play a critical role in regulation of various cellular functions, signal transduction pathways, and normal

\begin{tabular}{|c|c|c|c|c|}
\hline \multirow{2}{*}{$\begin{array}{c}\text { IC }_{\mathbf{5 0}} \text { Values } \\
\mathbf{( \mu g / m l )}\end{array}$} & \multicolumn{2}{|c|}{ MCF-7 } & \multicolumn{2}{c|}{ HEK-293 } \\
\cline { 2 - 5 } & $\mathbf{2 4} \mathbf{h}$ & $\mathbf{4 8} \mathbf{~ h}$ & $\mathbf{2 4} \mathbf{h}$ & $\mathbf{4 8} \mathbf{~ h}$ \\
\hline Etop & 142.67 & 111.71 & 606.45 & 574.72 \\
\hline GNP & 1938.98 & 1096.49 & 2727.75 & 2574.91 \\
\hline EGNP & 74.14 & 43.09 & 1337.49 & 1185.85 \\
\hline
\end{tabular}

Table 1: $I C_{50}$ value $(\mu \mathrm{g} / \mathrm{mL})$ of Etop, GNP and EGNP post $24 \mathrm{~h}$ and $48 \mathrm{~h}$ of treatment against MCF-7 and HEK Cell Line at $37^{\circ} \mathrm{C}$ under $5 \% \mathrm{CO}_{2}$. The cytotoxicity was tested by MTT assay at different concentrations of the formulations. All data are presented as means $\pm \mathrm{SD}(\mathrm{n}=3)$. Etop conc. $=100 \mu \mathrm{g} / \mathrm{ml}$ and equal volume GNP was used.

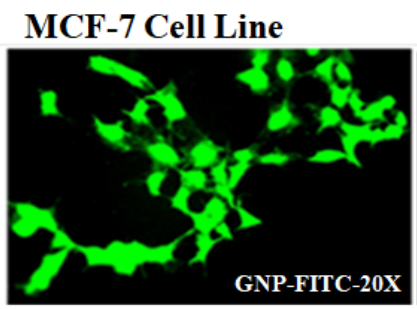

\section{HEK Cell Line}

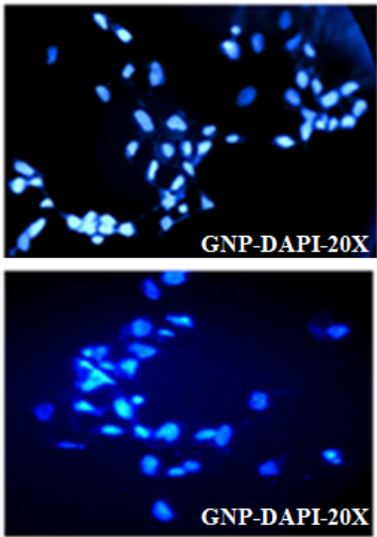

Figure 2: Enhanced Cellular uptake of FITC-GNPs and DAPI on MCF-7 as compared to HEK cells (Mag 20x). metabolism of the cell [25]. Cellular ROS levels can be quantified in live cells by a staining technique that oxidizes DCFDA into a fluorescent compound DCF that was directly proportional to the amount of DCFDA oxidized to DCF. EGNP caused maximum $\mathrm{H}_{2} \mathrm{O}_{2}$ generation in MCF-7 cells followed by Etop and GNP (Figure 5). Low fluorescence intensity in the HEK-293 cells, post treatments indicated the differential uptake between cancer and normal cells, thereby the cancer cells were more prone to generation of $\mathrm{H}_{2} \mathrm{O}_{2}$

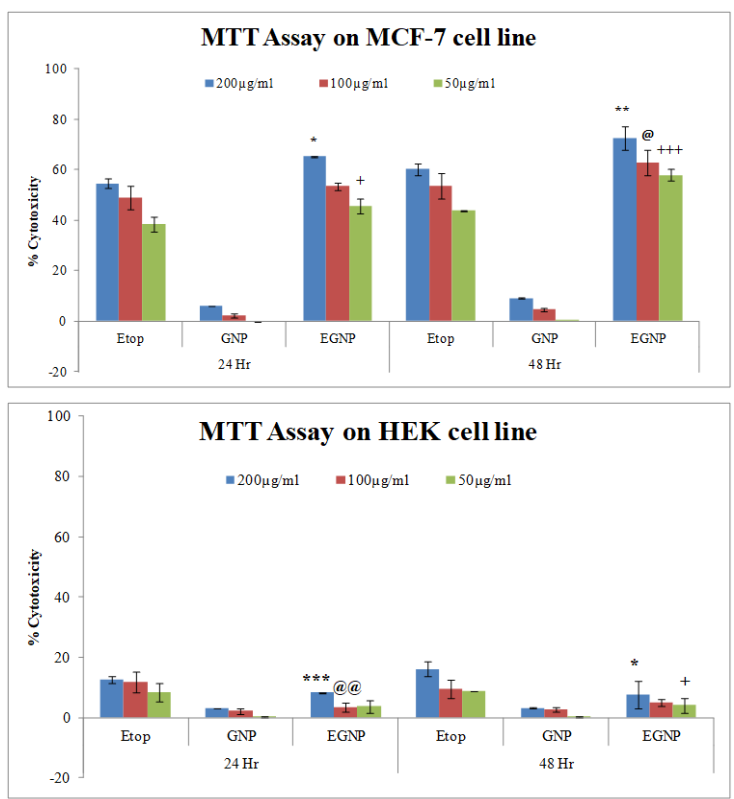

Figure 3: Time and concentration dependent effect of Etop and EGNP on (A) MCF-7 cell line and (B) HEK cell line. Data were expressed in mean \pm S.E.M $(\mathrm{N}=3)$.

*denotes significant difference between Etop vs. EGNP of conc. $200 \mu \mathrm{g} / \mathrm{ml}$ @ denotes significant difference between Etop vs. EGNP of conc. $100 \mu \mathrm{g} / \mathrm{ml}$; + denotes significant difference between Etop vs. EGNP of conc. $50 \mu \mathrm{g} / \mathrm{ml}$ ${ }^{*} p<0.05 ;{ }^{* *} p<0.01 ; p<0.001$

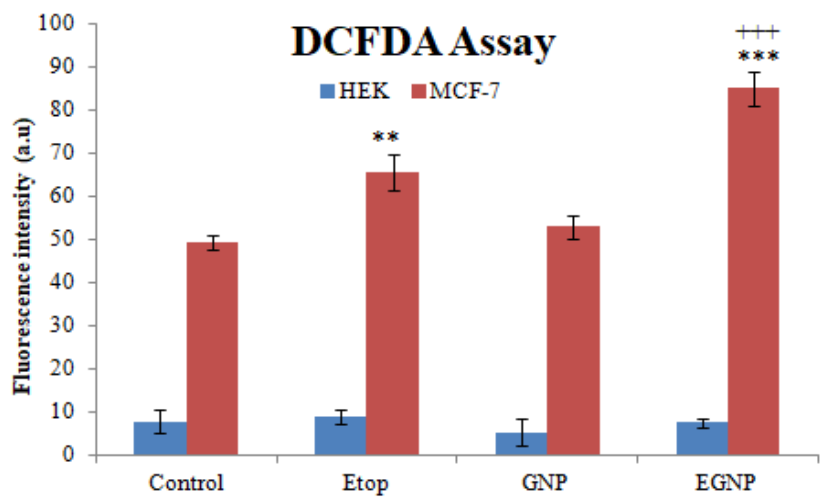

Figure 4: Estimation of ROS generation by DCFDA staining generation in MCF-7 and HEK cell line.

Maximum ROS generation was induced by EGNP in MCF-7. Data were expressed in mean \pm S.E.M $(\mathrm{N}=3)$. Etop conc. $=100 \mu \mathrm{g} / \mathrm{ml}$ and equal volume GNP was used.

*denotes significant difference between Control vs. Respective groups.

+ denotes significant difference between Etop $(100 \mu \mathrm{g} / \mathrm{ml})$ vs. EGNP $(100 \mu \mathrm{g} /$ $\mathrm{ml}$ )

${ }^{*} p<0.05 ;{ }^{* *} p<0.01 ;{ }^{* * *} p<0.001$ 
Citation: Moin I, Biswas L, Mittal D, Leekha A, Kumari N, et al. (2018) Crosstalk of ER Stress, Mitochondrial Membrane Potential and ROS Determines Cell Death Mechanisms Induced by Etoposide Loaded Gelatin Nanoparticles in MCF-7 Breast Cancer Cells. J Nanomed Nanotechnol 9 : 513. doi: $10.4172 / 2157-7439.1000513$

Page 5 of 9

Moreover, biotoxicity of Etop, GNP and EGNP was assessed on MCF-7 and HEK-293 cells by estimating the levels of LDH and RNS. A significant marker for cells undergoing necrosis is the plasma membrane permeabilization, and measuring the release of the enzyme lactate dehydrogenase (LDH) [26]. Traditionally, cell demise is estimated by determining the plasma membrane damage. Basically there are two categories of cytotoxicity assays for measuring necrosis: one that are based on the differential uptake of DNA binding dyes, that do not traverse the plasma membrane of living cells, eg. propidium iodide; and the others that are centred on the intracellular leakage through an impaired plasma membrane. The cytoplasmic enzyme LDH is ubiquitously present in nearly all the cells and is expelled through the damaged plasma membrane into the extracellular space.

Another subclass of ROS are the reactive nitrogen species that describes NO radicals and products that are formed by its reaction with the superoxide anions, e.g. peroxynitrite and nitrous oxide radicals [27]. The tumoricidal properties of NO have also been reported and utilized in the treatment of various types of cancer [28]. Results from $\mathrm{LDH}, \mathrm{NO}$ assay depicted that release of $\mathrm{LDH}$, generation of RNS were significantly enhanced in cells treated with EGNP followed by Etop and GNP in MCF-7 cell line whereas, there was negligible LDH release and RNS generation post EGNP treatment in HEK-293 cell line, indicating

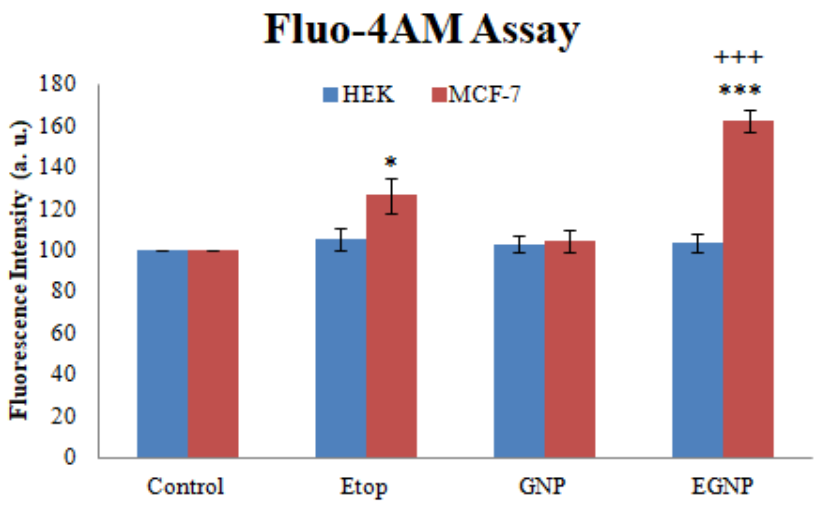

Figure 5: Etop and EGNPs induced increase in $\mathrm{Ca}^{2+}$ and ER stress activation. Cells were loaded with Fluo-4 AM, and Calcium release was observed in MCF and HEK cell lines.

Data were expressed in mean \pm S.E.M $(\mathrm{N}=3)$. Etop conc $=100 \mu \mathrm{g} / \mathrm{ml}$ and equal volume GNP was used.

*denotes significant difference between Control vs. Respective groups.

+ denotes significant difference between Etop $(100 \mu \mathrm{g} / \mathrm{ml}) v s$. EGNP(100 $\mu \mathrm{g} /$ $\mathrm{ml})$

${ }^{*} p<0.05 ;{ }^{* *} p<0.01 ;{ }^{* * *} p<0.001$ that the normal cells were unaffected by the treatment (Table 2). The growth-inhibitory effects of therapy determined by LDH and NO assay were supportive with the results determined by MTT assay.

Although the fundamental mechanisms activated by EGNP are yet unclear, numerous biochemical alterations can be attributed to generation of oxidative stress. GSTs are important detoxifying intracellular enzymes that catalyse the binding of the electophile to GSH that further protects by restoring $S$-thiolated proteins and simultaneously eliminating the ROS [29]. To abate the deleterious effects of oxidative stress within the organelle, the mitochondria possess antioxidants like GSH, SOD and GPx, GR that exist on either side of the membrane [30]. Hence, the antioxidant enzyme assay (GST, GSH, GPx, GR, SOD, NO, LDH) were evaluated in the MCF-7 and HEK-293 cells.

Reduced anti-oxidant levels were reported post treatment with EGNP, when compared to other treatment groups (Table 2). This observed decrease could possibly be due to the enhanced levels of lipid oxidation products that may be linked with the reduced availability of NADPH mandatory for the GR activity to convert GSSG to GSH. Reduced GSH/GSSG ratio coupled with GSH depletion were established markers of oxidative stress in various cancers [31]. Appreciating the physiological importance of ROS, the mechanisms of redox signalling at the cellular level requires additional elucidation and clarification. Redox-controlled signal transduction is often through the reverse oxidation of thiol proteins [32]. Thiol oxidation by Etop implicated that GSH gets oxidized directly by Etop and protein SH. Both exogenous and endogenous stimuli may generate ROS in cells. Endogenous production of ROS, mainly $\mathrm{O}_{2} \bullet^{-}$, arises essentially from leaking during the ETC activity in mitochondria. A powerful oxidant peroxynitrite $\left(\mathrm{ONOO}^{-}\right)$is generated when $\mathrm{O}_{2} \bullet^{-}$reacts with nitric oxide (NO•), a reactive nitrogen species (RNS). Alternately, $\mathrm{O}_{2} \bullet^{-}$is quickly dismutated into $\mathrm{O}_{2}$ and $\mathrm{H}_{2} \mathrm{O}_{2}$ by SOD [33]. Our results were in consonance with the reports published by Trachootham et al., [34] wherein, it was stated that cancer cells were more sensitive to further accumulation of ROS than normal cells. These characteristics offered a therapeutic window, wherein, cancer cells can be selectively targeted for cell death, while normal cells stay unaffected due to low physiological level of ROS. Therefore, EGNP was successful in targeting the redoxmodulating strategies

Since, induction of ER stress is a critical marker and is a potential target in cancer treatment [35]. It was imperative to elucidate the interplay of ROS generation with induction of ER stress. ER stores $\mathrm{Ca}^{2+}$ and mediates its transport across the ER, thereby playing a crucial role in maintenance of cytosolic $\mathrm{Ca}^{2+}$ concentrations [36]. Studies have

\begin{tabular}{|c|c|c|c|c|c|c|c|c|}
\hline \multicolumn{5}{|c|}{ MCF-7 } & \multicolumn{4}{|c|}{ HEK-293 } \\
\hline & Control & Etop & GNP & EGNP & Control & Etop & GNP & EGNP \\
\hline LDH & $0.91 \pm 0.1$ & $3.21 \pm 0.5^{* *}$ & $1.04 \pm 0.6$ & $1.23 \pm 0.3^{+}$ & $6.92 \pm 0.5$ & $10.84 \pm 0.9^{* *}$ & $8.41 \pm 0.6$ & $18.92 \pm 0.9^{* * * /+++}$ \\
\hline NO & $3.06 \pm 0.5$ & $8.83 \pm 0.8^{* * *}$ & $3.16 \pm 1.1$ & $6.94 \pm 0.9^{* *}$ & $6.30 \pm 0.1$ & $18.59 \pm 0.6^{\star \star *}$ & $12.82 \pm 0.8^{* * *}$ & $37.18 \pm 0.9^{* * *} /+++$ \\
\hline GST & $72.00 \pm 3.5$ & $164.71 \pm 8.3^{* * *}$ & $110.75 \pm 6.4^{* *}$ & $158.48 \pm 10.5^{* * *}$ & $478.40 \pm 9.1$ & $681.86 \pm 10.8$ & $511.65 \pm 7.2$ & $921.35 \pm 6.4^{* *} /+$ \\
\hline GSH & $106.84 \pm 7.4$ & $93.59 \pm 7.6$ & $120.38 \pm 5.5^{*}$ & $92.66 \pm 10.1$ & $84.44 \pm 7.7$ & $46.17 \pm 7.6^{\star * *}$ & $69.99 \pm 8.3$ & $26.60 \pm 3.3^{* * *}$ \\
\hline SOD & $5.14 \pm 1.1$ & $4.19 \pm 1.1$ & $5.20 \pm 0.5$ & $5.27 \pm 2.1$ & $3.29 \pm 0.4$ & $2.48 \pm 0.5$ & $2.59 \pm 1.0$ & $1.27 \pm 0.6^{*}$ \\
\hline GP & $92.34 \pm 0.7$ & $90.52 \pm 0.8^{*}$ & $99.86 \pm 0.6^{* * *}$ & $100.49 \pm 0.5^{* \star * /+++}$ & $3.29 \pm 0.4$ & $2.48 \pm 0.5^{\star \star \star}$ & $2.59 \pm 1.0^{* * *}$ & $1.27 \pm 0.6^{* * * /+++}$ \\
\hline GR & $60.83 \pm 5.8$ & $50.83 \pm 5.3$ & $65.55 \pm 11.2$ & $55.80 \pm 6.2$ & $27.74 \pm 5.6$ & $19.74 \pm 5.8$ & $24.90 \pm 12.6$ & $4.21 \pm 1.1^{* *}$ \\
\hline
\end{tabular}

Table 2: Evaluation of Biochemicals assays [LDH ( $\mu \mathrm{M} / \mathrm{min} / \mathrm{mg}$ protein), NO ( $\mu \mathrm{M} / \mathrm{min} / \mathrm{mg}$ protein), GST (NM/min $/ \mathrm{mg} \mathrm{protein),} \mathrm{GSH} \mathrm{(nM/min/mg} \mathrm{protein),} \mathrm{SOD} \mathrm{(ng/mg}$ protein), $\mathrm{GP}(\mathrm{nM} / \mathrm{min} / \mathrm{mg}$ protein), $\mathrm{GR}(\mathrm{nM} / \mathrm{min} / \mathrm{mg}$ protein) in HEK cell line and MCFcell line. All data are presented as means $\pm \mathrm{SD}(\mathrm{n}=3)$. Etop conc. $=100 \mu \mathrm{g} / \mathrm{ml}$ and equal volume GNP was used.

*denotes significant difference between Control vs. Respective groups.

+ denotes significant difference between Etop $(100 \mu \mathrm{g} / \mathrm{ml}) v s$. EGNP(100 $\mu \mathrm{g} / \mathrm{ml})$.

${ }^{*} p<0.05 ;{ }^{* *} p<0.01 ;{ }^{* * *} p<0.001$ 
Citation: Moin I, Biswas L, Mittal D, Leekha A, Kumari N, et al. (2018) Crosstalk of ER Stress, Mitochondrial Membrane Potential and ROS Determines Cell Death Mechanisms Induced by Etoposide Loaded Gelatin Nanoparticles in MCF-7 Breast Cancer Cells. J Nanomed Nanotechnol 9: 513. doi: $10.4172 / 2157-7439.1000513$

Page 6 of 9

reported that elevated cytosolic $\mathrm{Ca}^{2+}$ levels affects mitochondrial $\mathrm{Ca}^{2+}$ concentrations. $\mathrm{Ca}^{2+}$ was released from the ER stores and gets loaded into the mitochondria during apoptosis [37]. It is well known that cell death mechanisms are activated due to increase in intracellular $\mathrm{Ca}^{2+}$ levels that has toxic effects on the cell [38]. Intracellular $\mathrm{Ca}^{2+}$ ion homeostasis plays a distinct part in determining the fate of the cell and is often associated with cell signalling, proliferation, gene transcription and programmed cell death [39]. Perturbation of intracellular signalling of $\mathrm{Ca}^{2+}$ has been associated with both necrotic and apoptotic cell death, whereby, enhanced cytosolic $\mathrm{Ca}^{2+}$ possibly induces apoptosis [40], while sustained increased level promotes necrosis. These variances may directly affect mitochondrial function in response $\mathrm{Ca}^{2+}$ signals. Under pathophysiological conditions these organelles respond to increase in cytosolic $\mathrm{Ca}^{2+}$ that are confined to a small area by stimulus-metabolism coupling that possibly generates $\mathrm{NAD}(\mathrm{P}) \mathrm{H}$, thereby generating reductive intermediates that gives ATP the respiratory transport chain [41-44]. Mitochondrial calcium concentrations are dependent on those in the cytoplasm that in turn are dependent on sustained $\mathrm{Ca}^{2+}$ flux through channels of the ER/SR and the plasma membrane [45]. Overload of cellular $\mathrm{Ca}^{2+}$ is believed to be the cause of cytotoxicity and generally results in cell demise by necrosis, apoptosis or even autophagy.

Intracellular $\mathrm{Ca}^{2+}$ concentrations were assessed by Flou-4AM assay which indicated the highest intracellular concentration of $\mathrm{Ca}^{2+}$ in MCF-7 cells treated with EGNP (Figure 5). The increase of $\mathrm{Ca}^{2+}$ elicited by EGNPs could be because of their rapid destruction due to their translocation through lysosomes, endosomes in cancer cells during intracellular activities which are rich in the number of hydrolases in the acidic environment [46].

The irregular scattering of ions and protons on either side of the mitochondrial membrane generates the mitochondrial membrane potential (MMP). Reduced MMP may cause the opening of the transition pores that cause mitochondrial permeability, leading to the release of the pro-apoptotic molecules, the mitochondrial matrix releases Cyt C into the cytosol, resulting in the initiation of caspase- 9 that initiates the mitochondrial apoptotic pathway. Decrease in the MMP and production of ROS is coupled with disruption of oxidative phosphorylation, ultimately causing swelling and rupturing of the

\section{Mitochondrial membrane Potential}

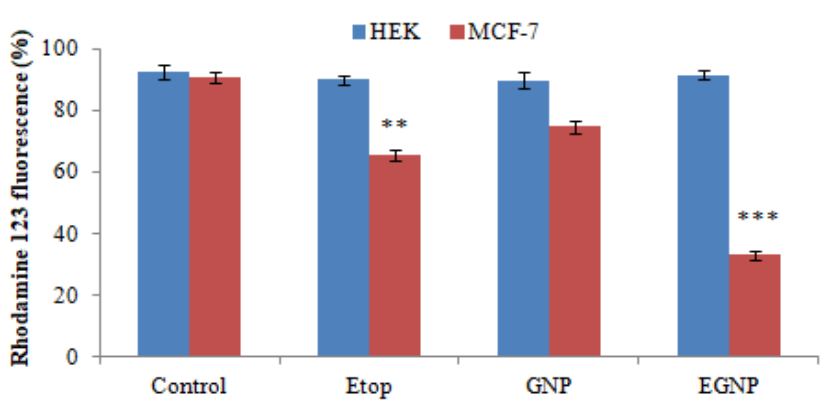

Figure 6: Effects of Etop, GNP and EGNP on disruption of MMP on HEK Cell line and MCF-7 Cell line. Significant loss of MMP was observed in MCF-7 cells treated with EGNP followed by Etop and GNP, whereas negligible effect was reported on HEK cells. Data were expressed in mean \pm S.E.M $(\mathrm{N}=3)$. Etop conc. $=100 \mu \mathrm{g} / \mathrm{ml}$ and equal volume GNP was used.

*denotes significant difference between Control vs. Respective groups.

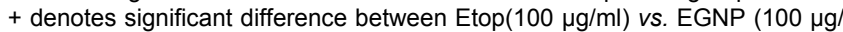
$\mathrm{ml})$.

${ }^{*} \mathrm{p}<0.05 ;{ }^{* *} \mathrm{p}<0.01 ;{ }^{* * *} \mathrm{p}<0.001$ organelle. Alterations in the MMP was analysed using mitochondriaselective dye, Rhodamine 123, an indicator of MMP that is internalised in the mitochondrial matrix of the living cells based on the existing MMP, using a flow cytometer. But during apoptosis, the membrane integrity is destabilized by the opening of the transition pores that increase the mitochondria permeability resulting in the release of Rhodamine 123 from mitochondria hence diminished fluorescence. Hence the $\operatorname{MMP}\left(\Delta \psi_{\mathrm{m}}\right)$ alterations can be optically measured as a ratio of the yellow-green fluorescence intensity that may occur during apoptosis. Flow cytometry analysis indicated reduced uptake of dye by GNPs reflecting by loss of $\Delta \psi \mathrm{m}$. The MMP also decreased in EGNPs by $63.34 \%$ in $24 \mathrm{~h}$, thus substantiating that EGNPs perturbed the mitochondrial function, leading to the disruption of $\Delta \psi \mathrm{m}$ in larger proportion than Etop per se $(27.82 \%$ in $24 \mathrm{hr}$ ) and GNPs ( $17.45 \%$ in 24 hr) that lead the cells towards cell demise (Figure 6).

It is believed that mitochondria plays a fundamental role in the execution of the apoptotic, necroptotic and the necrosis program [47]. This may further result in a cascade of events causing activation of caspase-3, eventually leading to cell apoptosis.

Apoptosis occurs under a variety of physiological and pathological conditions. Nucleosomal fragmentation of DNA is one of the most prominent biological features of apoptosis [48]. DPA is a quantitative and useful biochemical confirmatory assay for measuring apoptosis by determining the percentage of fragmentation [49]

Maximum fragmentation of DNA was observed with EGNP treated MCF-7 cells, when compared with GNP and Etop treated cells. In HEK-293, 7\% DNA fragmentation was observed, post treatment with EGNP while negligible DNA fragmentation was induced by GNPs i.e. $4 \%$ (Figure 7 ).

Even though the molecular mechanisms of apoptosis are not very well understood, literature definitely suggested that the caspases family, seem to play a vital role in commencing the process. Susin et al. [50] also showed that disruption of mitochondrial transmembrane potential leads to the release of an apoptosis inducing factor, which in a cell free in vitro system causes isolated nuclei to undergo apoptotic changes. Since, necroptosis shares several upstream signalling

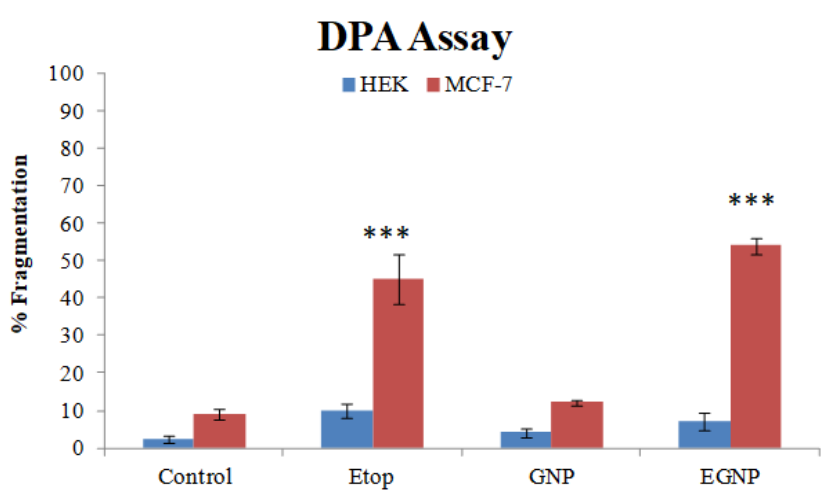

Figure 7: DNA fragmentation induced by Etop and EGNP on MCF-7 cell line and HEK cell line.

Maximun DNA fragmentation induced by EGNP in MCF-7. Data were expressed in mean + S.E.M $(\mathrm{N}=3)$. Etop conc. $=100 \mu \mathrm{g} / \mathrm{ml}$ and equal volume GNP was used.

*denotes significant difference between Control vs. Respective groups. + denotes significant difference between Etop(100 $\mu \mathrm{g} / \mathrm{ml}) v s$. EGNP(100 $\mu \mathrm{g} /$ $\mathrm{ml}$ ).

${ }^{*} p<0.05 ;{ }^{* *} p<0.01 ;{ }^{* *} p<0.001$ 
Citation: Moin I, Biswas L, Mittal D, Leekha A, Kumari N, et al. (2018) Crosstalk of ER Stress, Mitochondrial Membrane Potential and ROS Determines Cell Death Mechanisms Induced by Etoposide Loaded Gelatin Nanoparticles in MCF-7 Breast Cancer Cells. J Nanomed Nanotechnol 9 : 513. doi: $10.4172 / 2157-7439.1000513$

molecules with apoptosis, bivariate analysis by AnnexinV/PI analysis of MCF-7 cells were used to distinguish late apoptotic or necrotic cells from necroptotic cells. FACs analysis indicated $25.1 \%, 0.02 \%, 6.07 \%$ in apoptosis, $0.3 \%, 4.7 \%, 23.39 \%$ in necrosis and $2.05 \%, 0.4 \%, 65.83 \%$ in necroptosis post treatment with Etop, GNP and EGNP respectively Figures 8 and 9 . The cells undergoing necroptosis have prominent staining nuclei, whereas DNA in apoptotic cells and cells undergoing necrosis will have homogenous staining.
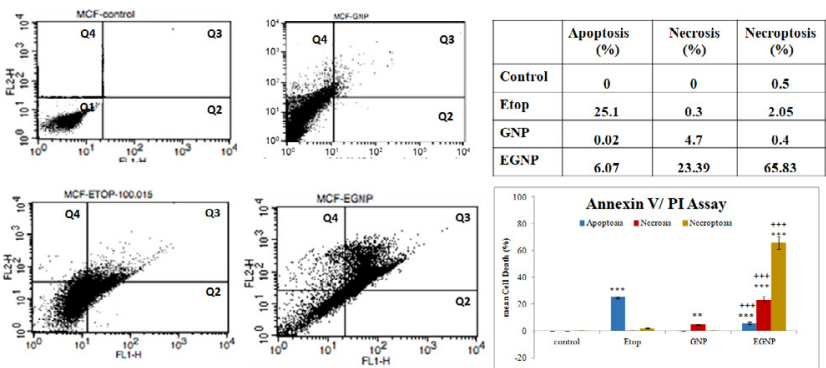

Annexin V/PIAssay
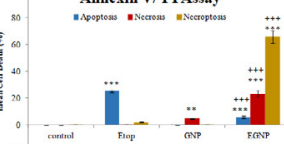

Figure 8: Scatter analysis with Annexin V/propidium iodide (PI) staining represents the percentage of cells undergoing Apoptosis, Necrosis and Necroptosis by Etop per se, GNP and EGNP in MCF-7 cells. Q1 quadrant represents viable cells. Q2, Q3, Q4 represent Apoptosis, Necrosis and Necroptosis, respectively. Etop conc. $=100 \mu \mathrm{g} / \mathrm{ml}$ and equal volume GNP was used.

*denotes significant difference between Control vs. Respective groups.

+ denotes significant difference between Etop $(100 \mu \mathrm{g} / \mathrm{ml}) v \mathrm{~s}$. EGNP(100 $\mu \mathrm{g} /$ $\mathrm{ml})$.

${ }^{*} p<0.05 ;{ }^{* *} p<0.01 ;{ }^{* * *} p<0.001$

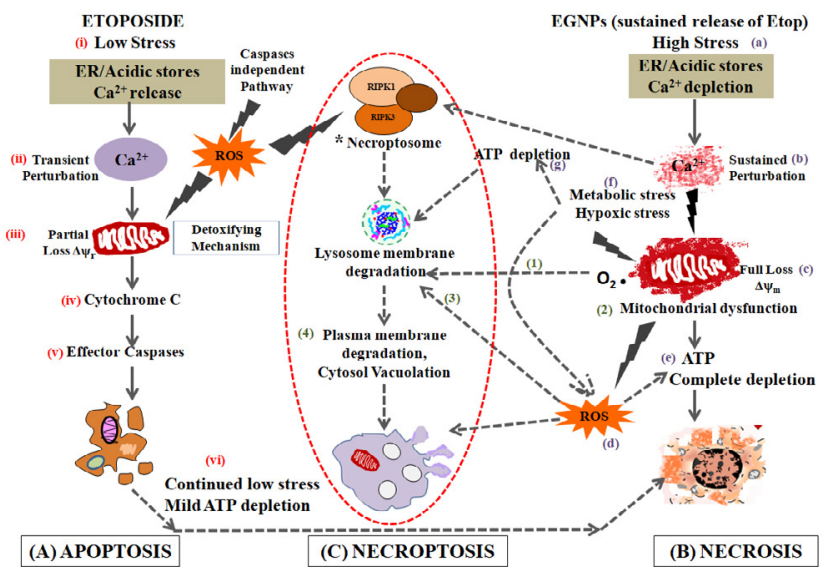

Figure 9: Simplified scheme of the Cell Death Mechanisms.

ER stress induces mitochondrial dysfunction with loss of MMP that modulates the cell demise pathway.

(i) Low ER stress causes (ii) transient perturbation leading to limited $\mathrm{Ca}^{2+}$ release causing (iii) partial disruption of mitochondrial membrane. This may release proapoptotic molecules, (iv) cyt $C$ and (v) effector caspases leading to (A) APOPTOSIS. (vi) Sustained low stress and low ATP stimulates mitochondrial permeabilization, triggers necrotic cell demise. Caspaseindependent apoptosis can also be trigerred by ROS accumulation. Alternately, (a) high ER stress causes (b) sustained perturbation resulting in excess release of $\mathrm{Ca}^{2+}$ stores, resulting in (c) full loss of mitochondrial function which further generates (d) ROS, (e) ATP depletion directing the cell towards (B) NECROSIS. Excess mitochondrial dysfunction liberates (1) $\mathrm{O}_{2}^{-}$which further contributes to the (2) ROS accumulation and (3) lysosome membrane degradation. This induces excess cytosol vacuolation propelling the cell to undergo programmed necrosis- (C) NECROPTOSIS. Continued (f) metabolic and hypoxic insults may enhance mitochondrial dysfunction resulting in more (g) "ATP depletion".

"Necroptosome can be formed by other mechanisms although it does not appear to have a role in mitochondrial dependent necroptosis.
It is hypothesized that Etop per se causes low stress in cells that caused release of $\mathrm{Ca}^{2+}$. Low ER stress causes transient perturbations of the MMP. This loss of partial MMP combined with metabolic insults stimulates ROS rgeneration and pro-apoptotic signals. On the other hand, high stress due to sustained release of Etop from EGNPs causes continuous ER stress and depletion of $\mathrm{Ca}^{2+}$ stores. The sustained $\mathrm{Ca}^{2+}$ depletion causes full loss of MMP triggering the cell to die via necrosis. The $\mathrm{Ca}^{2+}$ pool in the mitochondria is small under normal physiological conditions but can rise dramatically under diseased or pathological conditions. Since the ER lies in close proximity to mitochondria, it can influence the release of $\mathrm{Ca}^{2+}$ from ER thereby increase its concentration in the cytosol, which in-turn is taken up by the mitochondria through a $\mathrm{Ca}^{2+}$ uniporter. The matrix $\mathrm{Ca}^{2+}$ concentration correspondingly plays a crucial role in stimulating the $\mathrm{Ca}^{2+}$ sensitive matrix dehydrogenases that deliver NADH for ATP production and oxidative phosphorylation. Accumulation of free radicals can also lead to cell death by necrosis/ apoptosis. When cells are exposed to modest doses of ROS the cells are more likely to induce autophagy. Mitochondrial based apoptosis seems to be engaged in mitochondrial permeability transition pore (MPTP) complex, whose molecular aspect is still unclear [51,52].

It is important to understand the role of intracellular ATP levels in the crosstalk between apoptosis and necrosis. It has been suggested that high ATP levels characteristically directs the cell to undergo apoptosis, but low levels of ATP promotes necrosis. Therefore, the energy requirements flip the trigger from apoptsis to necrosis, based on the depletion of intracellular ATP levels [46,47]. Necrosis requires some levels of ATP, but complete depletion of ATP elicits yet another cellular death pathway that is mechanistically and morphologically different called necroptosis, that emerges as an interplay from both apoptosis and necrosis [53].

The commitment and the implementation phases of necroptosis are still to be explored. It has been observed that the swelling of organelle and the rupture of the plasma membrane are quite comparable to that of necrosis -the classical type III. The dynamic changes in the lysosomal, mitochondrial and the plasma membrane integrity, during characteristic forms of programmed necrosis i.e. necroptosis, secondary necrosis and $\mathrm{H}_{2} \mathrm{O}_{2}$-induced necrosis were investigated by Vandenabeele et al [54]. It was considered to be a type of cell death that recompenses for the inhibition of apoptosis, owing to definite cellular contexts or maybe caused by cancer,viruses, etc [32].

From its earliest description, cell death by necroptosis has been assumed to involve mitochondria and ROS [55]. Apoptosis can be induced by Etop either through caspases dependent pathways that are rapid or slow, caspase independent pathways [56]. Since, both the pathways were accentuated with EGNPs, it can be hypothesized that necroptosis being ROS and MMP mediated, and caspasesindependent [57]. It is well accepted that necroptosis is generally dependent on RIP3, which is activated following phosphorylation by the serine/threonine kinase RIP1 [58]. RIP3 probably induces a switch in the cell's metabolism, that leads to the increase in the production of mitochondrial ROS that climaxes in cell death [59-60]. Moreover, necroptosis may represent an alternative form of death which can substitute apoptosis when caspase activation is blocked. Studies to experimentally prove the blocking of caspases to prove necroptosis in our system are ongoing. Necroptosis undoubtedly represents an important process for enhancing tumor cell sensitivity to anticancer treatments and therefore its potentiation may represent an important therapeutic opportunity to kill tumor cells, particularly those resistant to apoptosis. Our hypothesis of sustained ER stress, ROS, MMP 
Citation: Moin I, Biswas L, Mittal D, Leekha A, Kumari N, et al. (2018) Crosstalk of ER Stress, Mitochondrial Membrane Potential and ROS Determines Cell Death Mechanisms Induced by Etoposide Loaded Gelatin Nanoparticles in MCF-7 Breast Cancer Cells. J Nanomed Nanotechnol 9 : 513. doi: $10.4172 / 2157-7439.1000513$

mediated necroptosis may explain at least in part why, although the ancestral form of cell death is often hidden by other cell death forms, it resumes as a back-up mechanism when the other pathways are blocked. It is well known that the mitochondria of a cancer cell are dysfunctional that exhibit enhanced DNA mutations and decreased oxidative phosphorylation. These can be proposed as potential targets for cancer therapy. As far as the correlation of cell-specific toxicity in cancer cells with mitochondrial targeting, our results were consistent with the previously reported results.

\section{Conclusion}

We report synthesis of improved $\mathrm{pH}$ sensitive gelatin nanocarriers having size $\sim 150 \mathrm{~nm}$; PDI 0.257 ; The morphological characterization indicated a spherical shape and size that was in unison with the DLS. Etoposide, a low molecular weight drug and with high hydrophobicity was encapsulated in GNPs. The therapeutic effect is reached upon hydrolysis inside the target cells to release the Etop. Cellular Uptake of FITC-GNPs in MCF-7 was significantly higher as compared to HEK293 cells. Enhanced DCFDA intensity indicated higher ROS generation in MCF-7 as compared to HEK-293 cell line. EGNPs induced increased intracellular $\mathrm{Ca}^{2+}$ in MCF-7 indicating enhanced sensitivity of cancer cells to lower concentration of Etop. The dual functional Etop acts as a pro-oxidant toward intracellular thiols in the cells as this redox activity of Etop contributes possibly to its genotoxicity and its carcinogenic potential to its antitumor efficacy. Appreciating the intracellular biochemical redox paradox of Etop may influence the progress and advancement of antioxidant strategies for safer and more efficient clinical use of Etop. In conclusion, necroptosis is emerging as an important process closely interconnected with apoptosis and represents a promising field for innovative therapeutic approaches.

\section{Acknowledgement}

IM is thankful to CSIR for his SRF, LB and DM are thankful fo their UGC-JRF. $A L$ and NK are thankful to DBT for their respective JRF\& SRF. This work was done without any financial assistance.

\section{Conflict of Interest}

No conflict of interest declared

\section{References}

1. https://livemint.com/Science/UaNco9nvoxQtxjneDS4LoO/India-still-has-a-lowbreast-cancer-survival-rate-of-66-st.htm

2. Sinkule JA (1984) Etoposide: a semisynthetic epipodophyllotoxin chemistry, pharmacology, pharmacokinetics, adverse effects and use as an antineoplastic agent. Pharmacotherapy 4: 61-71.

3. Rodman JH, Murry DJ, Madden T, Santana VM. Altered etoposide pharmacokinetics and time to engraftment in pediatric patients undergoing autologous bone marrow transplantation. J Clin Oncol 1994; 12: 2390-2397.

4. Hande KR (1998) Etoposide: four decades of development of a topoisomerase II inhibitor. Eur J Cancer 34: 1514-1521.

5. Demel HR, Feuerecker B, Piontek G, Seidl C, Blechert B, et al. (2015) Effects of topoisomerase inhibitors that induce DNA damage response on glucose metabolism and PI3K/Akt/mTOR signaling in multiple myeloma cells. Am J Cancer Res 5: 1649-1654.

6. Zhang SH, Huang Q (2013) Etoposide induces apoptosis via the mitochondrialand caspase-dependent pathways and in non-cancer stem cells in Panc-1 pancreatic cancer cells. Oncology Reports 30: 2765-2770.

7. Chiu CC, Lin CH, Fang K (2005) Etoposide (VP-16) sensitizes p53 deficient human non-small cell lung cancer cells to caspase-7-mediated apoptosis. Apoptosis 10: 643-650.

8. Vethakanraj HS, Sesurajan BP, Padmanaban VP, Jayaprakasam M, Mural S, Sekar AK (2018) Anticancer effect of acid ceramidase inhibitor ceranib-2 in human breast cancer cell lines MCF-7, MDA MB-231 by the activation of
SAPK/JNK, p38 MAPK apoptotic pathways, inhibition of the Akt pathway, downregulation of ERa. Anti-cancer drugs 29:50-60.

9. Joel SP, Shah R, Slevin ML (1994) Etoposide dosage and pharmacodynamics Cancer Chemother Pharmacol 34: S69-S75.

10. De Jong WH, Borm PJ (2008) Drug delivery and nanoparticles: applications and hazards. Int J Nanomedicine 3:133-149.

11. Kaul G, Amiji M (2002) Long-circulating poly (ethylene glycol)-modified gelatin nanoparticles for intracellular delivery. Pharm Res 19: 1061-1067.

12. Jeong B, Bae YH, Lee DS, Kim SW (1997) Biodegradable block copolymers as injectable drug-delivery systems. Nature 388: 860-862.

13. Elzoghby AO (2013) Gelatin-based nanoparticles as drug and gene delivery systems: reviewing three decades of research. J Control Release 172: 10751091

14. Patlolla RR, Vobalaboina V (2008) Folate-targeted etoposide-encapsulated lipid nanospheres. Journal of drug targeting 16:269-275.

15. Coester C, Kreuter J, von Briesen H, Langer K (2000) Preparation of avidinlabelled gelatin nanoparticles as carriers for biotinylated peptide. Int J Pharm 196: 147-149.

16. Saxena A, Sachin K, Bohidar HB, Verma AK (2005) Effect of molecular weight heterogeneity on drug encapsulation efficiency of gelatin nano-particles. Colloids Surf B Biointerfaces 45: 42-48.

17. Verma AK, Sachin K, Saxena A, Bohidar HB (2005) Release kinetics from bio-polymeric nanoparticles encapsulating protein synthesis inhibitorcycloheximide, for possible therapeutic applications. Curr Pharm Biotechnol 6 : 121-130.

18. Kumar V, Leekha A, Tyagi A, Mishra AK, Verma AK, et al. (2017) Preparation and evaluation of biopolymeric nanoparticles as drug delivery system in effective treatment of rheumatoid arthritis. Pharm Res 34: 654-667.

19. Gercel-Taylor C (2005) Diphenylamine assay of DNA fragmentation for chemosensitivity testing. Methods Mol Med 11: 79-82.

20. Mohankumar K, Pajaniradje S, Sridharan S, Singh VK, Ronsard L, et al. (2014) Mechanism of apoptotic induction in human breast cancer cell, MCF-7, by an analog of curcumin in comparison with curcumin-an in vitro and in silico approach. Chem Biol Interact 210: 51-63.

21. Wang SF, Liu LF, Wu MY, Cai CZ, Su H, et al. (2017) Baicalein prevents 6-OHDA/ascorbic acid-induced calcium-dependent dopaminergic neuronal cell death. Sci Rep 7: 8398

22. Sureda FX, Escubedo E, Gabriel C, Comas J, Camarasa J, et al. (1997) Mitochondrial membrane potential measurement in rat cerebellar neurons by flow cytometry. Cytometry 28: 74-80.

23. Mosmann T (1983) Rapid colorimetric assay for cellular growth and survival application to proliferation and cytotoxicity assays. J Immunol Methods 65: 55-63.

24. Berridge MV, Herst PM, Tan AS (2005) Tetrazolium dyes as tools in cell biology new insights into their cellular reduction. Biotechnol Annu Rev 11: 127-152.

25. Poli G, Leonarduzzi G, Biasi F, Chiarpotto E (2004) Oxidative stress and cell signalling. Curr Med Chem 11: 1163-1182.

26. Chan FKM, Moriwaki K, De Rosa MJ (2013) Detection of necrosis by release of lactate dehydrogenase activity. Methods Mol Biol 979: 65-70.

27. Brown GC (2010) Nitric oxide and neuronal death. Nitric oxide 23: 153-165.

28. Lechner M, Lirk P, Rieder J (2005) Inducible nitric oxide synthase (iNOS) in tumor biology: the two sides of the same coin. Semin Cancer Biol 15: 277-289.

29. Van Bladeren PJ (2000) Glutathione conjugation as a bioactivation reaction Chem Biol Interact 29: 61-76.

30. Pias EK, Aw TY (2002) Early redox imbalance mediates hydroperoxide-induced apoptosis in mitotic competent undifferentiated PC-12 cells. Cell Death Differ 9: 1007-1016.

31. Zitka O, Skalickova S, Gumulec J, Masarik M, Adam V, et al. (2012) Redox status expressed as GSH: GSSG ratio as a marker for oxidative stress in paediatric tumour patients. Oncol Lett 4: 1247-1253.

32. Redza-Dutordoir M, Averill-Bates DA (2016) Activation of apoptosis signalling pathways by reactive oxygen species. Biochimica et Biophysica Acta (BBA)Molecular Cell Research 1863:2977-2992. 
Citation: Moin I, Biswas L, Mittal D, Leekha A, Kumari N, et al. (2018) Crosstalk of ER Stress, Mitochondrial Membrane Potential and ROS Determines Cell Death Mechanisms Induced by Etoposide Loaded Gelatin Nanoparticles in MCF-7 Breast Cancer Cells. J Nanomed Nanotechnol 9 : 513. doi: $10.4172 / 2157-7439.1000513$

Page 9 of 9

33. Winterbourn CC (2015) Are free radicals involved in thiol-based redox signalling? Free Radic Biol Med 80: 164-170

34. Trachootham D, Alexandre J, Huang P (2009) Targeting cancer cells by ROSmediated mechanisms: a radical therapeutic approach? Nature reviews Drug discovery 8: 579-591.

35. Mandl J, Mészáros T, Bánhegyi G, Csala M (2013) Minireview: endoplasmic reticulum stress: control in protein, lipid, and signal homeostasis. Mol Endocrinol 27: 384-393.

36. Hajnóczky G, Davies E, Madesh M (2003) Calcium signaling and apoptosis. Biochem Biophys Res Commun 304: 445-454.

37. Pinton P, Giorgi C, Siviero R, Zecchini E, Rizzuto R (2008) Calcium and apoptosis: ER-mitochondria $\mathrm{Ca} 2+$ transfer in the control of apoptosis. Oncogene 27: 6407.

38. Krebs J, Agellon LB, Michalak M (2015) $\mathrm{Ca}^{2+}$ homeostasis and endoplasmic reticulum (ER) stress: An integrated view of calcium signaling. Biochemical and biophysical research communications 460: 114-121.

39. Gerasimenko JV, Gerasimenko OV, Palejwala A, Tepikin AV, Petersen $\mathrm{OH}$ et al. (2002) Menadione-induced apoptosis: roles of cytosolic Ca2+ elevations and the mitochondrial permeability transition pore. J Cell Sci 115: 485-497.

40. Criddle DN, Gerasimenko JV, Baumgartner HK, Jaffar M, Voronina S, et al (2007) Calcium signalling and pancreatic cell death: apoptosis or necrosis?. Cell Death Differ 14: 1285-1294.

41. Rizzuto R, Brini M, Murgia M, Pozzan T (1993) Microdomains with high $\mathrm{Ca}^{2+}$ close to $\mathrm{IP}_{3}$-sensitive channels that are sensed by neighboring mitochondria. Science 262: 744-747.

42. Hajnóczky G, Robb-Gaspers LD, Seitz MB, Thomas AP (1995) Decoding of cytosolic calcium oscillations in the mitochondria. Cell 82: 415-424.

43. Voronina S, Sukhomlin T, Johnson PR, Erdemli G, Petersen OH, et al. (2002) Correlation of $\mathrm{NADH}$ and $\mathrm{Ca} 2+$ signals in mouse pancreatic acinar cells. J Physiol 539: 41-45.

44. Petersen $\mathrm{OH}(2005) \mathrm{Ca}^{2+}$ signalling and $\mathrm{Ca}^{2+}$-activated ion channels in exocrine acinar cells. Cell Calcium 38: 171-200.

45. Ermak G, Davies KJ (2002) Calcium and oxidative stress: from cell signaling to cell death. Mol Immunol 38: 713-721.

46. Eguchi Y, Shimizu S, Tsujimoto Y (1997) Intracellular ATP levels determine cell death fate by apoptosis or necrosis. Cancer Res 57: 1835-1840.

47. Baines C (2010) Role of the mitochondrion in programmed necrosis. Front Physiol 1: 156
48. Hooker DJ, Mobarok M, Anderson JL, Rajasuriar R, Gray LR, et al. (2012) A new way of measuring apoptosis by absolute quantitation of inter-nucleosomally fragmented genomic DNA. Nucleic Acids Res 40: e113-e113.

49. Gibb RK, Gercel-Taylor C (2000) Use of diphenylamine in the detection of apoptosis. Methods Mol Med 39: 679-680.

50. Susin SA, Zamzami N, Castedo M, Hirsch T, Marchetti P, et al. (1996) Bcl-2 inhibits the mitochondrial release of an apoptogenic protease. J Exp Med 184: 1331-1341.

51. Halestrap AP (2009) What is the mitochondrial permeability transition pore? J Mol Cell Cardiol 46: 821-831.

52. Castedo M, Hirsch T, Susin SA, Zamzami N, Marchetti P, et al. (1996) Sequential acquisition of mitochondrial and plasma membrane alterations during early lymphocyte apoptosis. J Immunol 157: 512-521.

53. McNamara CR, Ahuja R, Osafo-Addo AD, Barrows D, Kettenbach A, et al. (2013) Akt Regulates TNFa synthesis downstream of RIP1 kinase activation during necroptosis. PLoS One 8: e56576.

54. Vandenabeele P, Galluzzi L, Berghe TV, Kroemer G (2010) Molecular mechanisms of necroptosis: an ordered cellular explosion. Nature Reviews Molecular Cell Biology 11: 700.

55. Van Herreweghe F, Festjens N, Declercq W, Vandenabeele, P (2010) Tumor necrosis factor-mediated cell death: to break or to burst, that's the question. Cellular and Molecular Life Sciences 67: 1567-1579.

56. Degterev A, Huang Z, Boyce M, Li Y, Jagtap P, et al. (2005) Chemica inhibitor of nonapoptotic cell death with therapeutic potential for ischemic brain injury. Nature Chem Bio 1: 112-119.

57. Venkatesan T, Choi YW, Mun SP, Kim YK (2016) Pinus radiata bark extrac induces caspase-independent apoptosis-like cell death in MCF-7 human breast cancer cells. Cell biology and toxicology 32:451-464.

58. Cho Y, Challa S, Moquin D, Genga R, Ray TD, et al. (2009) Phosphorylationdriven assembly of the RIP1-RIP3 complex regulates programmed necrosis and virus-induced inflammation. Cell 137: 1112-1123.

59. Vanlangenakker N, Berghe TV, Bogaert $P$, Laukens B, Zobel K, et al. (2011) clAP1 and TAK1 protect cells from TNF-induced necrosis by preventing RIP1/RIP3-dependent reactive oxygen species production. Cell Death and Differentiation 18: 656 .

60. Zhang DW, Shao J, Lin J, Zhang N, Lu BJ, et al. (2009) RIP3, an energy metabolism regulator that switches TNF-induced cell death from apoptosis to necrosis. Science 325: 332-336. 